\title{
USING GAC TO CONTROL THMs IN DRINKING WATER. AN EXPERIMENTAL STUDY AT THE ATHENS WATER WORKS AND AN ECONOMIC EVALUATION OF THE METHOD
}

\author{
K. KOUMENIDES ${ }^{1}$ \\ N. SAKKAS ${ }^{2}$ \\ D.F. LEKKAS ${ }^{3}$ \\ N. XYLOURGIDIS ${ }^{1 *}$
}

\author{
1 University of the Aegean \\ Water and Air Quality Laboratory \\ http://www.aegean.gr/waql \\ GR 81100 Mytilene Greece
}

2 TEl of Crete

Laboratory of Environmental Informatics http://talos.stef.teiher.gr/nsak/index_uk.htm

GR 71500 Heraklion Greece

${ }^{3}$ Imperial College of Science, Technology and Medicine

London, UK

Received: 01/03/01

Accepted: 05/03/02
* to whom all correspondence should be addressed

\begin{abstract}
An experimental study has been carried out in an attempt to verify the efficiency of GAC (granular activated carbon) in removing THMs (trihalomethanes), and in particular $\mathrm{CHCl}_{3}, \mathrm{CHCl}_{2} \mathrm{Br}, \mathrm{CHClBr}_{2}$ and $\mathrm{CHBr}_{3}$ from drinking water.

The experiments have been conducted at a pilot scale filtering plant that was set up for the purpose, at the Athens Water Authority, at Galatsi.

This paper reports on the experimental procedure, the sampling technique, the analytical method used, the overall efficiency of the approach and finally also draws some first conclusions as to the economic justification of the method, in order to provide some insight on the additional costs of a possible fullscale use of the method.
\end{abstract}

KEY WORDS: Water filtration; drinking water quality; chlorination by-products

\section{INTRODUCTION}

THMs are dangerous by-products generated during water chlorination, a standard disinfection practice at the vast majority of water treatment plants across the world. They are well known for their detrimental health effects, cancer being one of the most serious. Potable water THM control has received late- ly attention at both policy and operational level. More stringent limits necessitate a continuous effort to reach technically efficient and cost effective means of controlling this serious risk.

Activated carbon is a material very often suggested as the best available technique in removing a number of contaminants from air and water (e.g. 
Oxenford et al., 1991). Such are the cases of VOCs (volatile organic chemicals), radon-222, organic mercury, etc. For water treatment, a number of studies have been carried out, (e.g. Hyde et al., 1987; Wiesner et al., 1987, etc.) considering the use of GAC filtration either as a sand replacement option (first stage GAC filtration) or in terms of separate GAC filters-adsorbers (second stage GAC filtration) especially focusing on their performance advantage in TOC removal vis-a-vis the conventional filters used for turbidity removal.

The effect of GAC in THM removal has also received extensive attention in the literature (Summers et al., 1993; Crittenden et al., 1991; Wiesner et al., 1987). These authors, besides the efficiency of GAC itself, consider also a number of side, yet very important, issues. Such are the optimum backwash conditions of GAC filters (Sakkas et al., 1996), the transport of GAC, etc. The significant cost of this material necessitates the minimisation of any operational material losses that may arise during transportation or non-optimal filter backwashing. As to the THM removal itself, it appears (Lykins et al., 1988) that GAC, in principle, operates efficiently, though it is stressed that further work and more data are needed to reach more stable conclusions. The overall efficiency is strongly related to the quality of the source waters as well as the chlorination practices, as these largely affect the initial THM concentrations.

With a key objective to evaluate the GAC efficiency, technical and economical, in combating THMs in potable water, this work provides an illustration of the experimental setting used as well as a presentation and analysis of the data collected.

\section{MATERIALS AND METHODS}

For carrying out the experiments seeking to investigate the GAC efficiency in removing THMs from potable water, a special 8" Plexiglas filtering pilot unit was set up at the water treatment plant at Galatsi. Special care was taken to simulate as closely as possible the materials used and the practices currently pursued at these water treatment facilities. In this sense, the filtering media consisted from three parts: an upper $47 \mathrm{~cm}$ layer of GAC, a middle $40 \mathrm{~cm}$ layer of sand, of the exactly same quality and grading as the one currently in use and a lower gravel part again of the same characteristics with the large scale filtering unit. The GAC was provided from Chemiviron
Carbon and was coded as Filasorb 830. Its technical characteristics were as follows: Uniformity coefficient 1.4, Iodine number 1000, Grading $10 \mathrm{x}$ 20 U.S mesh. Silicone sampling water tubes were used in order to avoid any adsorption of the THMs on the tube surfaces.

The inflow of the water in the experimental apparatus occurred under gravity. Again, plastic was completely avoided in the piping feeding the water to the filter; steel elements were used to avoid a possible adsorption of the THMs on the pipe inner surface. The apparatus used is shown in Figure 1.

The water used for the experiments was taken from the overflow of the water works sedimentation tanks; water from this source is also fed to the "real" water treatment filters. At this phase, the coagulant and the chlorine have already been added and the THMs have been generated during the water residence in the sedimentation tanks.

\section{THE EXPERIMENTAL PROCEDURE}

Overall 37 experiment cycles took place within a period of three months. During each cycle, data for the water flow, the filtration velocity and the pressure drop were registered and calculated. Parameters such as water turbidity, temperature and $\mathrm{pH}$ as well as the origin of the inflow water were taken from the data archives of the Water Company.

Samples were also taken from the filter column and were subject to a laboratory analysis. The aim of the sampling was to calculate the THM adsorption percentages from the GAC layer of the pilot plant with relation to the following two parameters:

- The depth $(\mathrm{cm})$ of the GAC column.

- The total operational time of the filter and the quantity of water it had processed (simulated through the, so called, "bed volume" parameter, to be defined in the following).

Four sampling sets were consistently collected from four respective experimental cycles, namely the $1^{\text {st }}$, the $4^{\text {th }}$, the $16^{\text {th }}$ and the $37^{\text {th }}$. Each of these sets consisted from four subsets, collected at four distinct time instances; at the very beginning of the experiment the first, somewhere between 4 and 6 hours the second, between 11 and 13 hours the third and at the end the fourth. There was, however, an exception to this routine. The $16^{\text {th }}$ cycle lasted only for 13 hours and so only three sampling subsets were collected.

Each subset consisted from 10 samples, which were 


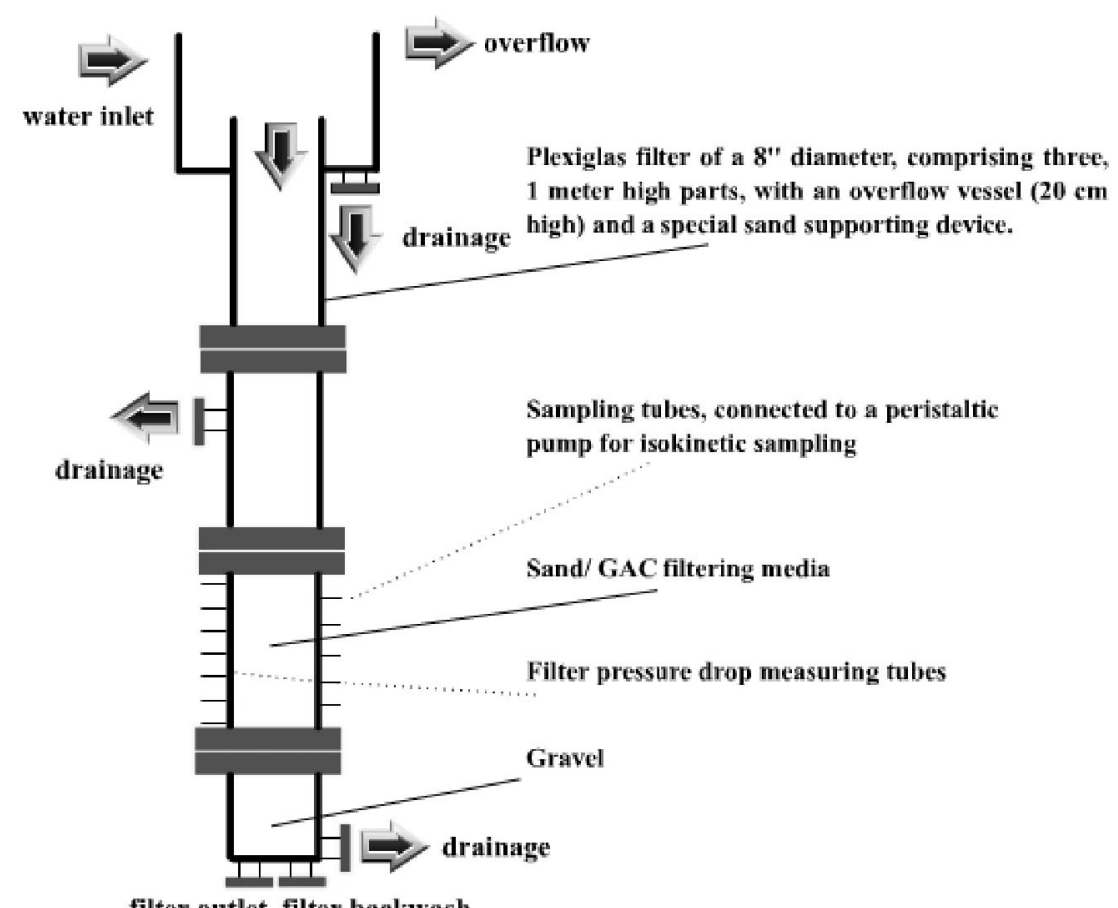

filter outlet filter backwash 니다

Figure 1. The experimental apparatus

extracted from the various depths of the filter; at zero level (top of filter) at 10, 20, 30, 40 and $50 \mathrm{~cm}$ within the GAC layer and at $60,70,80$ and $90 \mathrm{~cm}$ in the sand layer of the filter. The sand/ GAC interface was at $50 \mathrm{~cm}$ depth. A special peristaltic pump was used to ensure isokinetic sampling conditions.

\section{SAMPLE ANALYSIS}

For the determination of the THM concentrations in all the samples collected, the method of Liquid-Liquid Extraction-Gas ChromatographyECD was used, with a detection limit of $0.02 \mu \mathrm{g} \mathrm{l}^{-1}$ for all THMs. This is a particularly sensitive technique, with a great accuracy in measuring THMs. When applying the method, $10 \mathrm{ml}$ of the sample were extracted with $2 \mathrm{ml}$ of n-hexane, used for pesticide analysis and $1 \mu \mathrm{l}$ or the resulting extract was introduced in the Gas Chromatograph. The column used for the chromatographic separation of the various THM substances was fused silica capillary, with the following dimensions: $30 \mathrm{~m}$ length, $0.53 \mathrm{~mm}$ inner diameter and a $0.88 \mu \mathrm{m}$ thickness. The filling material was 5\% diphenyl, $95 \%$ dimethyl-polysixolane. Analyses were performed by means of a GC (HP 5890) with an electron-capture detector (Ni-ECD), supported from the HP 3365 Chemsation software (Version A 02.01). $\mathrm{N}_{2}$ was used both as carrying and auxiliary gas. The conditions under which the measurements were performed are summarised in Table 1. The total analysis and extraction time was approximately 2025 minutes per sample. The technique used for injecting the sample was the Cool-on-Column. The detailed control protocol includes analyses of THMs (with a certificate-EPA Method Mixture THMs No 713M, Polyscience), internal standard tetrachloroethylene, with ultrapure water free from organics, and water samples to which known standard concentrations are added, so that the accuracy in measuring THMs is fully controlled. The data on THM concentrations $\left(\mu \mathrm{g} \mathrm{l}^{-1}\right)$, registered during the four sampling cycles, are presented in Tables 2-5.

Table 1. Gas chromatography conditions for the determination of THMs in water samples

\begin{tabular}{|l|l|}
\hline Parameter & Value \\
\hline Carrier gas flow & $5 \mathrm{ml} \mathrm{min}-1$ \\
\hline Auxiliary gas flow & $10 \mathrm{ml} \mathrm{min}$ m $^{-1}$ \\
\hline Oven temperature $(\mathrm{T})$ & \\
\hline Initial temperature & $50{ }^{\circ} \mathrm{C}-3 \mathrm{~min}$ \\
\hline First temperature rise & $50{ }^{\circ} \mathrm{C}-80{ }^{\circ} \mathrm{C}$ \\
\hline Gradient of temperature rise & $10{ }^{\circ} \mathrm{C} \mathrm{m^{-1 }}$ \\
\hline Temperature of injector & $50{ }^{\circ} \mathrm{C}$ \\
\hline Temperature of detector & $300{ }^{\circ} \mathrm{C}$ \\
\hline
\end{tabular}


Table 2. Sampling set No. 1 (Experiment cycle No. 1)

\begin{tabular}{|c|c|c|c|c|c|c|c|c|c|c|c|c|c|c|c|c|c|c|c|c|}
\hline & \multicolumn{4}{|c|}{$\mathrm{CHCl}_{3}$} & \multicolumn{4}{|c|}{$\mathrm{CHCl}_{2} \mathrm{Br}$} & \multicolumn{4}{|c|}{$\mathrm{CHClBr}_{2}$} & \multicolumn{4}{|c|}{$\mathrm{CHBr}_{3}$} & \multicolumn{4}{|c|}{ Total THMs } \\
\hline $\mathrm{L}(\mathbf{c m})$ & $\mathbf{t}=\mathbf{0 h}$ & $t=6 h$ & $t=12 h$ & $t=22 h$ & $\mathbf{t}=\mathbf{0 h}$ & $t=6 h$ & $t=12 h$ & $t=22 h$ & $t=0 h$ & $t=6 h$ & $t=12 h$ & $\mathrm{t}=\mathbf{2 2 h}$ & $\mathrm{t}=\mathbf{0 h}$ & $t=6 h$ & $t=12 h$ & $t=22 h$ & $\mathbf{t}=\mathbf{0 h}$ & $t=6 h$ & $t=12 h$ & $t=22 h$ \\
\hline 0 & 2.8 & 1.9 & 2.2 & 1.7 & 8.3 & 7.3 & 7.3 & 5.8 & 6.1 & 5.9 & 5.5 & 4.2 & 0.9 & 0.8 & 0.8 & 0.5 & 18.1 & 15.9 & 15.8 & 12.2 \\
\hline 10 & 2.8 & 2.1 & 2 & 1.4 & 7.6 & 7.3 & 6.8 & 4.6 & 5.9 & 5.9 & 5.2 & 3.2 & 0.9 & 0.9 & 0.7 & 0 & 17.2 & 16.2 & 14.7 & 9.2 \\
\hline 20 & 0.8 & 0.7 & 1.2 & 0.5 & 2.9 & 3.1 & 4.3 & 2.2 & 2.2 & 2.3 & 3.1 & 1.6 & 0 & 0 & 0 & 0 & 5.9 & 6.1 & 8.6 & 4.3 \\
\hline 30 & 0 & 0 & 0 & 0 & 0.7 & 0.7 & 1.5 & 0.7 & 0.6 & 0.6 & 1.1 & 0.5 & 0 & 0 & 0 & 0 & 1.3 & 1.3 & 2.6 & 1.2 \\
\hline 40 & 0 & 0 & 0 & 0 & 0.6 & 0 & 1 & 0.6 & 0.6 & & 0.7 & 0.5 & 0 & 0 & 0 & 0 & 1.2 & 0 & 1.7 & 1.1 \\
\hline 50 & 0 & 0 & 0 & 0 & 0 & 0 & 0 & 0 & 0 & 0 & 0 & 0 & 0 & 0 & 0 & 0 & $\mathbf{0}$ & 0 & $\mathbf{0}$ & 0 \\
\hline 60 & 0 & 0 & 0 & 0 & 0 & 0 & 0 & 0 & 0 & 0 & 0 & 0 & 0 & 0 & 0 & 0 & $\mathbf{0}$ & $\mathbf{0}$ & $\mathbf{0}$ & $\mathbf{0}$ \\
\hline 70 & 0 & 0 & 0 & 0 & 0 & 0 & 0 & 0 & 0 & 0 & 0 & 0 & 0 & 0 & 0 & 0 & 0 & 0 & 0 & 0 \\
\hline 80 & 0 & 0 & 0 & 0 & 0 & 0 & 0 & 0 & 0 & 0 & 0 & 0 & 0 & 0 & 0 & 0 & $\mathbf{0}$ & $\mathbf{0}$ & $\mathbf{0}$ & 0 \\
\hline 90 & 0 & 0 & 0 & 0 & 0 & 0 & 0 & 0 & 0 & 0 & 0 & 0 & 0 & 0 & 0 & 0 & $\mathbf{0}$ & 0 & $\mathbf{0}$ & 0 \\
\hline
\end{tabular}

Table 3. Sampling set No. 1 (Experiment cycle No. 4)

\begin{tabular}{|c|c|c|c|c|c|c|c|c|c|c|c|c|c|c|c|c|}
\hline & \multicolumn{3}{|c|}{$\mathrm{CHCl}_{3}$} & \multicolumn{3}{|c|}{$\mathrm{CHCl}_{2} \mathrm{Br}$} & \multicolumn{3}{|c|}{$\mathrm{CHClBr}_{2}$} & \multicolumn{4}{|c|}{$\mathrm{CHBr}_{3}$} & \multicolumn{3}{|c|}{ Total THMs } \\
\hline $\mathbf{L}(\mathbf{c m})$ & $\mathbf{T}=\mathbf{0 h}$ & $t=5 h$ & $t=13 h$ & $\mathbf{t}=\mathbf{0 h}$ & $t=5 h$ & $t=13 h$ & $\mathbf{t}=\mathbf{0 h}$ & $t=5 h$ & $t=13 h$ & $t=0 h$ & $t=5 h$ & $t=13 h$ & $t=22 h$ & $t=0 h$ & $t=5 h$ & $t=13 h$ \\
\hline 0 & 1.6 & 1.9 & 1.8 & 5.3 & 6.4 & 5.3 & 4 & 4.7 & 4.2 & 0.5 & 0.5 & 0.6 & & 11.4 & 13.5 & 11.9 \\
\hline 10 & 0 & 0.6 & 0.8 & 0.6 & 1.4 & 2.6 & 0.5 & 0.7 & 1.6 & 0 & 0 & 0 & & 1.1 & 2.7 & 5 \\
\hline 20 & 0 & 0 & 0.5 & 0 & 0 & 0.8 & 0 & 0 & 0.6 & 0 & 0 & 0 & & $\mathbf{0}$ & $\mathbf{0}$ & 1.9 \\
\hline 30 & 0 & 0 & 0 & 0 & 0 & 0.6 & 0 & 0 & 0.5 & 0 & 0 & 0 & & $\mathbf{0}$ & $\mathbf{0}$ & 1.1 \\
\hline 40 & 0 & 0 & 0 & 0 & 0 & 0.5 & 0 & 0 & 0 & 0 & 0 & 0 & & $\mathbf{0}$ & 0 & 0.5 \\
\hline 50 & 0 & 0 & 0 & 0 & 0 & 0 & 0 & 0 & 0 & 0 & 0 & 0 & & $\mathbf{0}$ & $\mathbf{0}$ & $\mathbf{0}$ \\
\hline 60 & 0 & 0 & 0 & 0 & 0 & 0 & 0 & 0 & 0 & 0 & 0 & 0 & & 0 & 0 & $\mathbf{0}$ \\
\hline 70 & 0 & 0 & 0 & 0 & 0 & 0 & 0 & 0 & 0 & 0 & 0 & 0 & & $\mathbf{0}$ & 0 & $\mathbf{0}$ \\
\hline 80 & 0 & 0 & 0 & 0 & 0 & 0 & 0 & 0 & 0 & 0 & 0 & 0 & & $\mathbf{0}$ & 0 & $\mathbf{0}$ \\
\hline 90 & 0 & 0 & 0 & 0 & 0 & 0 & 0 & 0 & 0 & 0 & 0 & 0 & & 0 & 0 & $\mathbf{0}$ \\
\hline
\end{tabular}


Table 4. Sampling set No. 3 (Experiment cycle No. 16)

\begin{tabular}{|c|c|c|c|c|c|c|c|c|c|c|c|c|c|c|c|c|c|c|c|c|}
\hline & \multicolumn{4}{|c|}{$\mathrm{CHCl}_{3}$} & \multicolumn{4}{|c|}{$\mathrm{CHCl}_{2} \mathrm{Br}$} & \multicolumn{4}{|c|}{$\mathrm{CHClBr}_{2}$} & \multicolumn{4}{|c|}{$\mathrm{CHBr}_{3}$} & \multicolumn{4}{|c|}{ Total THMs } \\
\hline $\mathbf{L}(\mathbf{c m})$ & $t=0 h$ & $t=4 h$ & $t=11 h$ & $t=24 h$ & $\mathbf{t}=\mathbf{0 h}$ & $t=4 h$ & $t=11 h$ & $t=24 h$ & $\mathbf{t}=\mathbf{0 h}$ & $t=4 h$ & $t=11 h$ & $t=24 h$ & $t=0 h$ & $t=4 h$ & $\mathrm{t}=11 \mathrm{~h}$ & $t=24 h$ & $\mathbf{t}=\mathbf{0 h}$ & $t=4 h$ & $\mathrm{t}=11 \mathrm{~h}$ & $t=24 h$ \\
\hline 0 & & & & & 9.82 & 7.26 & 7.8 & 4.6 & 6.27 & 4.9 & 5.9 & 3.2 & 0.84 & 0.69 & 0.93 & 0 & 16.93 & 12.85 & 14.63 & 7.8 \\
\hline 10 & & & & & 1.5 & 2.75 & 2.34 & 2.2 & 0.68 & 1.73 & 1.25 & 1.6 & 0 & 0.25 & 0 & 0 & 2.18 & 4.73 & 3.59 & 3.8 \\
\hline 20 & & & & & 1 & 0.79 & 0.87 & 0.7 & 0.45 & 0.4 & 0.42 & 0.5 & 0 & 0 & 0 & 0 & 1.45 & 1.19 & 1.29 & 1.2 \\
\hline 30 & & & & & 0.93 & 1.04 & 0.73 & 0.6 & 0.43 & 0.52 & 0 & 0.5 & 0 & 0 & 0 & 0 & 1.36 & 1.56 & 0.73 & 1.1 \\
\hline 40 & & & & & 1 & 0.73 & 0.72 & 0 & 0.47 & 0 & 0 & 0 & 0 & 0 & 0 & 0 & 1.47 & 0.73 & 0.72 & 0 \\
\hline 50 & & & & & 0.68 & 0.61 & 0.64 & 0 & 0.39 & 0 & 0 & 0 & 0 & 0 & 0 & 0 & 1.07 & 0.61 & 0.64 & $\mathbf{0}$ \\
\hline 60 & & & & & 0.7 & 0.63 & 0.66 & 0 & 0.42 & 0 & 0 & 0 & 0 & 0 & 0 & 0 & 1.12 & 0.63 & 0.66 & $\mathbf{0}$ \\
\hline 70 & & & & & 0.72 & 0.6 & 0.66 & 0 & 0.44 & 0 & 0 & 0 & 0 & 0 & 0 & 0 & 1.16 & 0.6 & 0.66 & 0 \\
\hline 80 & & & & & 0.97 & 0.65 & 0.67 & 0 & 0.52 & 0 & 0 & 0 & 0 & 0 & 0 & 0 & 1.49 & 0.65 & 0.67 & $\mathbf{0}$ \\
\hline 90 & & & & & 0.59 & 0.57 & 0.62 & 0 & 0.4 & 0 & 0 & 0 & 0 & 0 & 0 & 0 & 0.99 & 0.57 & 0.62 & 0 \\
\hline
\end{tabular}

Note: $\mathrm{CHCl}_{3}$ data were rejected in this sampling set, because of a failure to conform to the sampling protocol

Table 5. Sampling set No. 4 (Experiment cycle No. 37)

\begin{tabular}{|c|c|c|c|c|c|c|c|c|c|c|c|c|c|c|c|c|c|c|c|c|}
\hline & \multicolumn{4}{|c|}{$\mathrm{CHCl}_{3}$} & \multicolumn{4}{|c|}{$\mathrm{CHCl}_{2} \mathrm{Br}$} & \multicolumn{4}{|c|}{$\mathrm{CHClBr}_{2}$} & \multicolumn{4}{|c|}{$\mathrm{CHBr}_{3}$} & \multicolumn{4}{|c|}{ Total THMs } \\
\hline $\mathrm{L}(\mathrm{cm})$ & $\mathbf{t}=\mathbf{0 h}$ & $t=6 h$ & $t=11 h$ & $t=24 h$ & $t=0 h$ & $t=6 h$ & $t=11 h$ & $t=24 h$ & $t=0 h$ & $t=6 h$ & $t=11 h$ & $t=24 h$ & $t=0 h$ & $t=6 h$ & $t=11 h$ & $t=24 h$ & $t=0 h$ & $t=6 h$ & $t=11 h$ & $t=24 h$ \\
\hline 0 & 3.1 & 4.03 & 2.81 & 2.97 & 5.79 & 7.41 & 5.07 & 5.86 & 2.7 & 3.26 & 2.25 & 2.88 & 0 & 0.2 & 0 & 0 & 11.59 & 14.9 & 10.13 & 11.71 \\
\hline 10 & 2.87 & 4.49 & 2.1 & 2.67 & 5.08 & 8.82 & 3.9 & 5.38 & 2.33 & 3.81 & 1.8 & 2.63 & 0 & 0 & 0 & 0 & 10.28 & 17.12 & 7.8 & 10.68 \\
\hline 20 & 2.61 & 4.37 & 2.47 & 0 & 3.1 & 5.14 & 3.39 & 0 & 1.12 & 2.06 & 1.3 & 0 & 0 & 0 & 0 & 0 & 6.83 & 11.57 & 7.16 & $\mathbf{0}$ \\
\hline 30 & 2 & 2.89 & 1.46 & 1.845 & 2.14 & 2.93 & 1.75 & 2.22 & 0.78 & 1.245 & 0.66 & 0.85 & 0 & 0 & 0 & 0 & 4.92 & 7.065 & 3.87 & 4.915 \\
\hline 40 & 1.25 & 3.48 & 2.2 & 2.26 & 1.3 & 3.1 & 2.15 & 2.42 & 0.53 & 1.3 & 0.73 & 0.86 & 0 & 0 & 0 & 0 & 3.08 & 7.88 & 5.08 & 5.54 \\
\hline 50 & 2.43 & 1.76 & 1.56 & 1.82 & 2.67 & 1.66 & 1.51 & 1.72 & 1.02 & 0.59 & 0.56 & 0.62 & 0 & 0 & 0 & 0 & 6.12 & 4.01 & 3.63 & 4.16 \\
\hline 60 & 2.58 & 2.03 & 1.86 & 2.09 & 2.85 & 1.81 & 1.735 & 1.99 & 0.98 & 0.63 & 0.605 & 0.68 & 0 & 0 & 0 & 0 & 6.41 & 4.47 & 4.2 & 4.76 \\
\hline 70 & 2.62 & 1.93 & 1.76 & 2.18 & 2.99 & 1.77 & 1.72 & 2.09 & 1.01 & 0.61 & 0.6 & 0.7 & 0 & 0 & 0 & 0 & 6.62 & 4.31 & 4.08 & 4.97 \\
\hline 80 & 2.63 & 2.17 & 2.26 & 2.07 & 2.94 & 2.06 & 2.06 & 2.03 & 0.98 & 0.67 & 0.68 & 0.68 & 0 & 0 & 0 & 0 & 6.55 & 4.9 & 5 & 4.78 \\
\hline 90 & 2.75 & 2.18 & 1.91 & 1.84 & 3.09 & 1.82 & 1.82 & 1.85 & 1.02 & 0.66 & 0.61 & 0.63 & 0 & 0 & 0 & 0 & 6.86 & 4.66 & 4.34 & 4.32 \\
\hline
\end{tabular}




\section{RESULTS}

From the data collected during this work, it was possible to calculate the bed volumes corresponding to all four sampling tests. Bed volume is defined as the ratio of the water volume that has been filtered through the GAC filter divided by the volume of the GAC filter media itself. This is a very important parameter that helps analyse the behaviour of the GAC filter as a function of the amount of the water filtered. These results are shown in Table 6.

Table 6. GAC filter volume and bed volumes of the sampling tests

\begin{tabular}{|l|l|}
\hline GAC column depth & $0.47 \mathrm{~m}$ \\
\hline Inner filter diameter & $0.19 \mathrm{~m}$ \\
\hline GAC volume & $0.0133 \mathrm{~m}^{3}$ \\
\hline Bed volume of $1^{\text {st }}$ sampling test & 495 \\
\hline Bed volume of $2^{\text {nd }}$ sampling test & 1899 \\
\hline Bed volume of $3^{\text {rd }}$ sampling test & 6033 \\
\hline Bed volume of $4^{\text {th }}$ sampling test & 13662 \\
\hline
\end{tabular}

The data of the four sampling sets were then normalised against the concentration at level $0 \mathrm{~cm}$. In this way, the relevant concentrations of THMs were calculated at all sampling depths in the GAC filter. The data produced for the total THM concentrations at the various depths are shown in Table 7.

Next, the columns of Table 7, which correspond to the subsets of a particular set, were averaged. This is justified as the GAC condition is not expected to differ significantly between the subsets of the same sampling set. This is equivalent to stating that the bed volume during any particular sampling set is approximately constant, which is intuitively acceptable.

Figure 2 illustrates in a concise way the performance of the GAC filter and how this is affected by time or, equivalently, by the volume of the filtered water. The following conclusions may be drawn from the above experimental analysis:

Table 7. Relative concentrations of TTHMs for all sampling sets as a function of GAC filter depth

\begin{tabular}{|c|c|c|c|c|c|c|c|c|}
\hline & \multicolumn{5}{|c|}{$1^{\text {st }}$ sampling set } & \multicolumn{3}{|c|}{$2^{\text {nd }}$ sampling set } \\
\hline $\mathrm{L}(\mathrm{cm})$ & $t=0 h$ & $t=6 h$ & $\mathrm{t}=12 \mathrm{~h}$ & & & $t=0 h$ & $t=5 h$ & $t=13 h$ \\
\hline 0 & 1.00 & 1.00 & 1.00 & & & 1.00 & 1.00 & 1.00 \\
\hline 10 & 0.95 & 1.02 & 0.93 & & & 0.10 & 0.20 & 0.42 \\
\hline 20 & 0.33 & 0.38 & 0.54 & & & 0.00 & 0.00 & 0.16 \\
\hline 30 & 0.07 & 0.08 & 0.16 & & & 0.00 & 0.00 & 0.09 \\
\hline 40 & 0.07 & 0.00 & 0.11 & & & 0.00 & 0.00 & 0.04 \\
\hline 50 & 0.00 & 0.00 & 0.00 & & & 0.00 & 0.00 & 0.00 \\
\hline 60 & 0.00 & 0.00 & 0.00 & & & 0.00 & 0.00 & 0.00 \\
\hline 70 & 0.00 & 0.00 & 0.00 & & & 0.00 & 0.00 & 0.00 \\
\hline 80 & 0.00 & 0.00 & 0.00 & & & 0.00 & 0.00 & 0.00 \\
\hline \multirow[t]{2}{*}{90} & 0.00 & 0.00 & 0.00 & & & 0.00 & 0.00 & 0.00 \\
\hline & \multicolumn{4}{|c|}{$3^{\text {rd }}$ sampling set } & \multicolumn{4}{|c|}{$4^{\text {th }}$ sampling set } \\
\hline $\mathrm{L}(\mathrm{cm})$ & $t=0 h$ & $t=4 h$ & $t=11 h$ & $t=24 h$ & $\mathbf{t}=\mathbf{0 h}$ & $t=6 h$ & $\mathrm{t}=11 \mathrm{~h}$ & $t=24 h$ \\
\hline 0 & 1.00 & 1.00 & 1.00 & 1.00 & 1.00 & 1.00 & 1.00 & 1.00 \\
\hline 10 & 0.13 & 0.37 & 0.25 & 0.49 & 0.89 & 1.15 & 0.77 & 0.91 \\
\hline 20 & 0.09 & 0.09 & 0.09 & 0.15 & 0.59 & 0.78 & 0.71 & 0.00 \\
\hline 30 & 0.08 & 0.12 & 0.05 & 0.14 & 0.42 & 0.47 & 0.38 & 0.42 \\
\hline 40 & 0.09 & 0.06 & 0.05 & 0.00 & 0.27 & 0.53 & 0.50 & 0.47 \\
\hline 50 & 0.06 & 0.05 & 0.04 & 0.00 & 0.53 & 0.27 & 0.36 & 0.36 \\
\hline 60 & 0.07 & 0.05 & 0.05 & 0.00 & 0.55 & 0.30 & 0.41 & 0.41 \\
\hline 70 & 0.07 & 0.05 & 0.05 & 0.00 & 0.57 & 0.29 & 0.40 & 0.42 \\
\hline 80 & 0.09 & 0.05 & 0.05 & 0.00 & 0.57 & 0.33 & 0.49 & 0.41 \\
\hline 90 & 0.06 & 0.04 & 0.04 & 0.00 & 0.59 & 0.31 & 0.43 & 0.37 \\
\hline
\end{tabular}




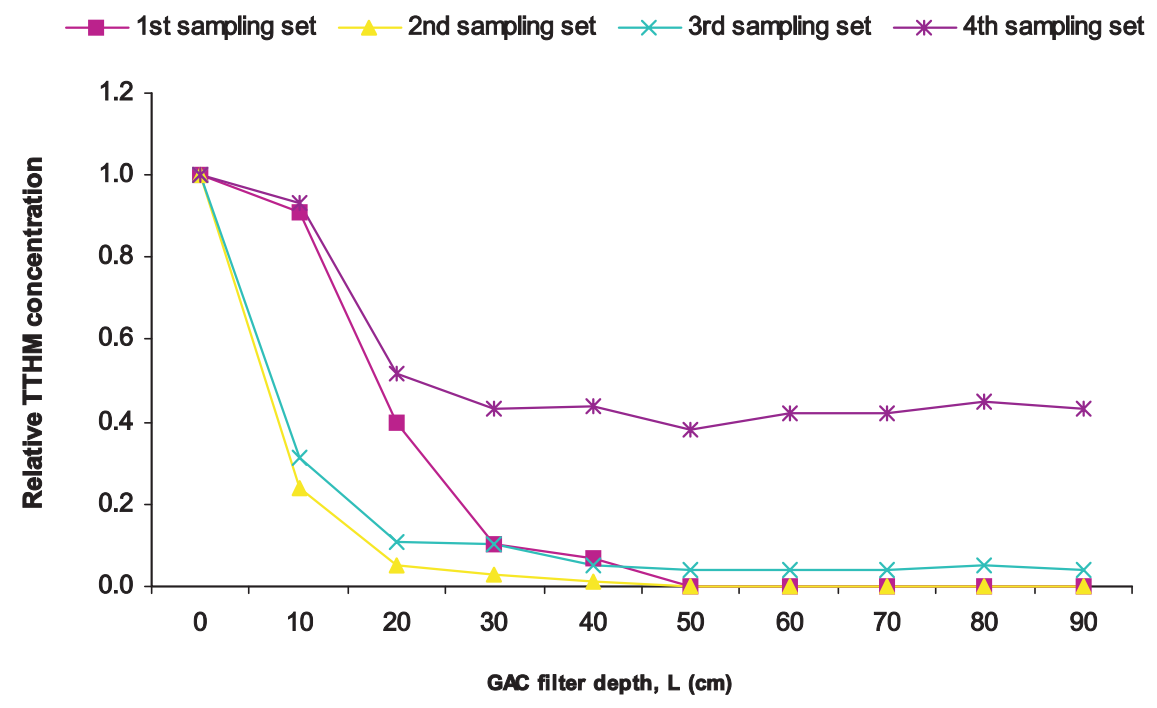

Figure 2. Variation of TTHM concentration along the GAC filter depth for all four sampling sets

- For the first three sampling tests (bed volumes up to approximately 6,000 ) it was observed that at the GAC filter removed practically about $90 \%$ of the overall water THMs. This truly appeared to be an excellent performance.

- For the fourth sampling test (bed volume approximately 13,000 ) however, which admittedly was located far away in time from the other three, or equivalently corresponded to a much higher bed volume, the GAC filter seemed to have become somewhat saturated, as it appeared to be removing only approximately the $60 \%$ of the water TTHMs.

As an overall conclusion, it can be stated that the GAC performance is absolutely efficient in removing the TTMHs up to a bed volume of approximately 10,000. This figure will also be used in the financial evaluation of the method that follows in the next paragraph.

\section{FINANCIAL CONSIDERATIONS}

From a practical point of view, a critical issue of our analysis would be to estimate the additional water treatment cost that results from the inclusion of a GAC filtration unit, in order to remove THMs from drinking water. More accurately, one should rather consider the increase of the price the Water Authority charges for an $\mathrm{m}^{3}$ of tap water, should GAC filtering be introduced as a standard procedure. Simply put, to reflect the additional cost on the price of the water and not on the cost of its production means that all associated costs reach directly the consumer and do not affect at all the profitability of the Water Company.

The price of an $\mathrm{m}^{3}$ of treated water is therefore the departing point. At the moment of the compilation of this text we estimate this figure to approximately $0.45 €$ per $\mathrm{m}^{3}$. The reasoning behind this is as follows. The Athens Water Authority pricing policy is discriminated; a practice widely opted for by similar authorities worldwide. In fact, the price rises sharply about $50 \%$ after the first $15 \mathrm{~m}^{3}$ of the household consumption. The low price, for the first consumption range, between 0 and $15 \mathrm{~m}^{3}$, is approximately $0.35 €$ per $\mathrm{m}^{3}$. After this consumption threshold the price rises to $0.54 €$ per $\mathrm{m}^{3}$. For the purposes of this preliminary assessment an average price of $0.45 €$ per $\mathrm{m}^{3}$ is well justified.

Also, the assumption was made that the investment cost for the introduction of a GAC filtering process would be minor, though not totally negligible, when compared to its operational cost (material replenishment) or the other processes infrastructural costs. Therefore, based on the cost of the raw material, we have increased this by $20 \%$ to approximately account for all other costs (infrastructure modifications, labor, etc.) incurred in implementing GAC filtering at the full scale. 
Table 8. Evaluation of additional treatment cost for THM removal by means of a GAC filter column (calculated for $1 \mathrm{~m}^{3}$ of treated water)

\begin{tabular}{|l|c|c|}
\hline \multicolumn{1}{|c|}{ Parameter } & Value & Explanation \\
\hline Volume of solid- liquid column of GAC $\left(\mathrm{m}^{3}\right)$ & $10^{-4}$ & $\begin{array}{c}\text { Effective bed } \\
\text { volume }=10,000\end{array}$ \\
\hline Volume of solid phase of GAC $\left(\mathrm{m}^{3}\right)$ & $0.38 \times 10^{-4}$ & $\begin{array}{c}\text { GAC column porosity } \\
(\text { dry })=0.38\end{array}$ \\
\hline Mass of GAC $(\mathrm{kg})$ & $1200 \times 0.38 \times 10^{-4}=0.045$ & GAC density $=1200 \mathrm{~kg} \mathrm{~m}^{-3}$ \\
\hline Purchase cost of required GAC $(€)$ & $4 \times 1200 \times 0.38 \times 10^{-4}=0.18$ & Cost of 1 Kg of GAC $=4 €$ \\
\hline Total costs associated with GAC filtering $(€)$ & $1.2 \times 0.18=0.21$ & $\begin{array}{c}\text { Estimated as } 120 \% \text { of the } \\
\text { material cost }\end{array}$ \\
\hline $\begin{array}{l}\text { Approximate price charged by the Water } \\
\text { Authority }(€)\end{array}$ & 0.45 & \\
\hline $\begin{array}{l}\text { Expected tap water price increase }(\%) \text { for effective } \\
(80-90 \%) \text { TTHM removal by means of GAC and with- } \\
\text { out affecting Water Authority profitability. }\end{array}$ & $0.21 / 0.45=\sim 49 \%$ & \\
\hline
\end{tabular}

Moreover, following the conclusions reached in the above paragraphs, as to the efficiency of the method, an assumption was made that an approximate bed volume of 10000 is the appropriate upper limit for replenishing the activated carbon.

All these assumptions are summarised in Table 8. Similar cost data are also published in the literature (Lykins et al., 1988). Here, a wide range of material cost data, ranging between 0.04 and 0.25 $\$$ per $\mathrm{m}^{3}$ of treated water have been reported. Though our estimation of a material cost of approximately $0.18 €$, per $\mathrm{m}^{3}$ of treated water, falls well in this reported range, it seems to be positioned more close to the upper (expensive) end of these cost estimations.

\section{SUMMARY}

The study provided some further analytical insight to the potential of GAC in controlling THMs in potable water. It was shown that GAC eliminates THMs from water for bed volumes up to 6000 , while at bed volumes of 13000 there is significant evidence that saturation is deteriorating its capability further to adsorb THMs in an equally successful way.

For a drastic elimination (e.g. 90\%) however of the THMs from potable water one should antici- pate an increase of the tap water price in the range of $50 \%$. An alternative option could certainly be to settle with lower removal rates, in the area of $50-60 \%$, in which case this price increase would significantly lower, to approximately 30$35 \%$ of the current water charges.

\section{RECOMMENDATIONS}

Further work is required, with experiments in the area of bed volumes between 6,000 and 13,000 as well as bed volumes well above 13,000 (e.g. 20,000). This would provide a better understanding of the dynamics by which the GAC behaviour deteriorates that would help better understand the precise costs that would result from the introduction of GAC filtering as a standard process in water treatment.

Conditions for mathematically modelling the THM removal rates seem to also be in place, as an ever-increasing number of data is already published in the literature. The possible influence of the inlet water quality and of the chlorination practices should be strongly considered in such models. This would provide insight to the rather varied removal performances that have been observed in practice and their direct implications on cost, should a full-scale implementation of the method be adopted. 


\section{REFERENCES}

Crittenden, J., Reddy, P., Arora, H., Trynoski, J., Hand, D., Perram, D. and Summers, R. (1991), Predicting GAC Performance with Rapid Small- Scale Column Tests, Journal AWWA, 77-87.

Golfinopoulos, S.K., Kostopoulou, M.N. and Lekkas, T.D. (1995), THM Formation in the High-Bromide Water Supply of Athens, In: Proceedings of the $4^{\text {th }}$ Conference on Environmental Science and Technology, Vol. A, 740-753, Molyvos, Greece.

Golfinopoulos, S.K., Kostopoulou, M.N. and Lekkas, T.D. (1994), Seasonal Variations in Trihalomethanes levels in the Water Supply System of Athens, In: Proceedings of the $6^{\text {th }}$ International Conference of Environmental Contamination, 16-17, Delphi, Greece.

Hyde, R., Hill, D., Zabel, T. and Burke, T. (1987), Replacing Sand with GAC in Rapid Gravity Filters, Journal AWWA, 33-49.

Lykins, B., Clark, R. and Adams, J. (1988), Granular Activated Carbon for Controlling THMs, Journal AWWA, 85-92.

Oxenford, J. and Lykins, B. (1991), Conference Summary: Practical Aspects of the Design and Use of GAC, Journal $A W W A$, 58-64.

Sakkas, N. and Lekkas, T. (1989), Hydrodynamic characteristics of the solid-liquid fluidised bed developing during the backwash of filter media, Environmental Technology, 10, 151-166.

Summers, R., Benz, M., Shukairy, H. and Cummings, L. (1993), Effect of Separation Processes on the Formation of Brominated THMs, Journal AWWA, 88-95.

Wiesner, M., Rook, J. and Fiessinger, F. (1997), Optimizing the Placement of GAC Filtration Units, Journal $A W W A, 39-49$. 